Article

\title{
Appropriate Drone Flight Altitude for Horse Behavioral Observation
}

\author{
Tomoko Saitoh * and Moyu Kobayashi
}

Citation: Saitoh, T.; Kobayashi, M. Appropriate Drone Flight Altitude for Horse Behavioral Observation. Drones 2021, 5, 71. https://doi.org/ $10.3390 /$ drones5030071

Academic Editor: Pablo Rodríguez-Gonzálvez

Received: 21 June 2021

Accepted: 22 July 2021

Published: 31 July 2021

Publisher's Note: MDPI stays neutral with regard to jurisdictional claims in published maps and institutional affiliations.

Copyright: (c) 2021 by the authors. Licensee MDPI, Basel, Switzerland. This article is an open access article distributed under the terms and conditions of the Creative Commons Attribution (CC BY) license (https:// creativecommons.org/licenses/by/ $4.0 /)$.
Field Center of Animal Science and Agriculture, Obihiro University of Agriculture and Veterinary Medicine, Obihiro 080-8555, Japan; m.kobayashi@hokuchiku.com

* Correspondence: tsaitoh@obihiro.ac.jp

\begin{abstract}
Recently, drone technology advanced, and its safety and operability markedly improved, leading to its increased application in animal research. This study demonstrated drone application in livestock management, using its technology to observe horse behavior and verify the appropriate horse-drone distance for aerial behavioral observations. Recordings were conducted from September to October 2017 on 11 horses using the Phantom 4 Pro drone. Four flight altitudes were tested (60, 50,40 , and $30 \mathrm{~m}$ ) to investigate the reactions of the horses to the drones and observe their behavior; the recording time at each altitude was $5 \mathrm{~min}$. None of the horses displayed avoidance behavior at any flight altitude, and the observer was able to distinguish between any two horses. Recorded behaviors were foraging, moving, standing, recumbency, avoidance, and others. Foraging was the most common behavior observed both directly and in the drone videos. The correlation coefficients of all behavioral data from direct and drone video observations at all altitudes were significant $(p<0.01)$. These results indicate that horse behavior can be discerned with equal accuracy by both direct and recorded drone video observations. In conclusion, drones can be useful for recording and analyzing horse behavior.
\end{abstract}

Keywords: horse; drone; behavioral observation; grazing; flight altitude

\section{Introduction}

Drone technology made great strides in recent years, with drastic improvements in safety and operability. Drones of various sizes and functions are commercially available and relatively easy to obtain. They are used extensively in several fields, including remote sensing, determining ecosystems' complexity, and disaster countermeasures. Drone application has many benefits; drones are inexpensive and relatively easy to operate compared with aerial photography, which requires airplanes and helicopters. Therefore, their application is increasing in the field of animal research. Drones are useful for observing animal behavior, especially in wildlife research and were used in related studies observing dugongs [1], elephants [2], red-crowned cranes [3], penguins [4], Antarctic shags [5], and Southern elephant seals [6].They can be used for behavioral surveys of animals inhabiting difficult-to-access areas and/or highly sensitive and aggressive animals.

Previous studies on horse behavior reported direct observations $[7,8]$ or observations from videos acquired using fixed-point cameras [9]. However, these methods are considerably labor-intensive. In addition, direct observation is observer-dependent and limited by the number of animals one can observe at once. Human presence can also affect horse behavior because horses read humans in various ways, such as through our body posture, facial expressions, and attentiveness [10]. Moreover, videos recorded with a fixed-point camera are limited by the field of view and blind spots.

We considered using drones in horse behavioral surveys as an example of their application to the field of livestock management. Aerial videos recorded by drones are valuable because their coverage is larger than that of a fixed-point camera, and they can quickly follow a target horse. Additionally, because the videos can be viewed offline by the 
observer, it is possible to avoid the time constraints of real-time observations. Moreover, since videos can be observed indoors, the environment around the observer is also more comfortable. Furthermore, it is challenging to simultaneously identify multiple horses during real-time visual observation. However, it is possible to identify multiple horses from a video by identifying each horse of interest and playing the recorded video multiple times.

In considering using drones in horse behavioral surveys, it is necessary to clarify the effects of drone usage on the natural behavior of horses. Unfortunately, only a few studies focusing on feral horse spatial relationships used drones on horse behavior [11-13] and leading feral ponies by a remotely operated quadcopter drone into simulated capture enclosures [14]. Therefore there are no studies on the natural behavior of domestic horses.

Furthermore, there were only a few instances of drone applications in livestock management, such as its utilization for cattle [15] and goats [16]. Therefore, it is necessary to determine the feasibility of using drones to assist with livestock management and livestock behavioral surveys.

In this experiment, the drone was flown over the horses at four altitudes to examine their reaction to the drone and their behavior that can be observed from the recorded drone video. Since the altitude was regarded as the distance between the horse and the drone, we investigated the recording distance that does not affect the horses. From the results of direct visual and recorded video behavioral observations, the drone application to horses' behavioral observation was considered.

\section{Materials and Methods}

The experimental procedures followed the Guide for the Care and Use of Agricultural Animals of Obihiro University (Obihiro, Hokkaido). The current study was conducted from September to October 2017 at the paddock and pasture at Obihiro University of Agriculture and Veterinary Medicine. Horses kept at the university were released into the paddock $(48 \mathrm{~m} \times 21 \mathrm{~m})$ or pasture $(65 \mathrm{~m} \times 46 \mathrm{~m})$, and their behavior was observed directly. Simultaneously, a video of the horses was captured by a camera attached to a drone, as described below.

\subsection{Drone and Camera}

A Phantom 4 Pro (DJI, Nanshan, China) drone was used, with a diagonal length of $350 \mathrm{~mm}$ and weight of $1.4 \mathrm{~kg}$. This drone has obstacle avoidance and automatic airborne position-holding functions that use an ultrasonic sensor. The attached camera was supported by a 3-axis gimbal and was set to face downwards at a $90^{\circ}$ angle. The camera lens had an automatic focus, with a viewing angle of $84^{\circ}(24 \mathrm{~mm})$. The video was recorded at $4 \mathrm{~K}(3840 \times 2160$ pixels) resolution with $60 \mathrm{fps}$ and saved in a micro-SD card (maximum 32 GB). The drone flight was conducted during the day according to the law [17], flying at an altitude between $30 \mathrm{~m}$ and $150 \mathrm{~m}$ at a location where the drone was visible.

\subsection{Horses, Paddock, and Pasture}

Eleven horses were kept at the Obihiro University of Agriculture and Veterinary Medicine (Obihiro, Hokkaido). Detailed data for each horse are shown in Table 1. Horses $\mathrm{A}$ and $\mathrm{B}$ and $\mathrm{C}$ and $\mathrm{D}$ were dam and foal pairs, respectively. Horses A-E usually used the paddock (as illustrated in Figure 1) and were recorded with other herd mates. Horses F-K were paired as focal and companion horses for this experiment. These horses were recorded with only one other pair in a pasture, sometimes used for grazing (as illustrated in Figure 1). They were introduced to the pasture more than $30 \mathrm{~min}$ before the drone flight to allow them to adapt to the pasture conditions. For the dam and foal pairs, the drone was focused on the dam alone if both were not simultaneously in the drone's view. The horses were fed with hay at both the paddock and pasture locations. 
Table 1. Filming location and horse details.

\begin{tabular}{|c|c|c|c|c|c|c|c|}
\hline \multicolumn{8}{|c|}{ Experiments in the paddock } \\
\hline \multirow{2}{*}{$\frac{\text { Pair No. }}{\text { Horse }}$} & \multicolumn{3}{|c|}{$\mathbf{I}$} & \multicolumn{2}{|c|}{ II } & \multicolumn{2}{|c|}{ III } \\
\hline & \multicolumn{2}{|r|}{ A } & \multirow{2}{*}{$\begin{array}{c}\text { B } \\
\text { Hokkaido } \\
\text { native }\end{array}$} & \multirow{2}{*}{$\begin{array}{c}\text { C } \\
\text { Hokkaido } \\
\text { native }\end{array}$} & \multirow{2}{*}{$\begin{array}{c}\text { D } \\
\text { Hokkaido } \\
\text { native }\end{array}$} & \multicolumn{2}{|c|}{$\mathrm{E}$} \\
\hline Breeds & & okkaido native & & & & \multicolumn{2}{|c|}{ Mixed pony } \\
\hline Age & & 8 years & 5 months & 7 years & 6 months & \multirow{3}{*}{\multicolumn{2}{|c|}{$\begin{array}{c}11 \text { years } \\
2017 / 9 / 24 \\
10: 27\end{array}$}} \\
\hline Flight & & $2017 / 9 / 21$ & $2017 / 9 / 21$ & $2017 / 10 / 21$ & $2017 / 10 / 21$ & & \\
\hline start & & $10: 29$ & 10:29 & $11: 57$ & $11: 57$ & & \\
\hline \multicolumn{8}{|c|}{ Experiments in the pasture } \\
\hline \multicolumn{2}{|c|}{ Pair No. } & \multicolumn{2}{|c|}{ IV } & \multicolumn{2}{|c|}{$\mathbf{V}$} & \multicolumn{2}{|c|}{ VI } \\
\hline \multicolumn{2}{|c|}{ Horse } & $\mathrm{F}$ & G & $\mathrm{H}$ & I & $\mathrm{J}$ & K \\
\hline \multicolumn{2}{|c|}{ Breeds } & Mixed & Mixed & Mixed & \multicolumn{2}{|c|}{ ThoroughbredMixed } & $\begin{array}{l}\text { Hokkaido } \\
\text { native }\end{array}$ \\
\hline & & 2 years & 8 years & 18 years & 23 years & 6 years & 23 years \\
\hline \multicolumn{2}{|c|}{ Flight start } & $\begin{array}{c}2017 / 9 / 5 \\
13: 55\end{array}$ & $\begin{array}{c}2017 / 9 / 26 \\
14: 19\end{array}$ & $\begin{array}{c}2017 / 9 / 13 \\
13: 55\end{array}$ & $\begin{array}{c}2017 / 9 / 27 \\
11: 37\end{array}$ & $\begin{array}{c}2017 / 9 / 22 \\
14: 46\end{array}$ & $\begin{array}{c}2017 / 9 / 27 \\
14: 41\end{array}$ \\
\hline
\end{tabular}

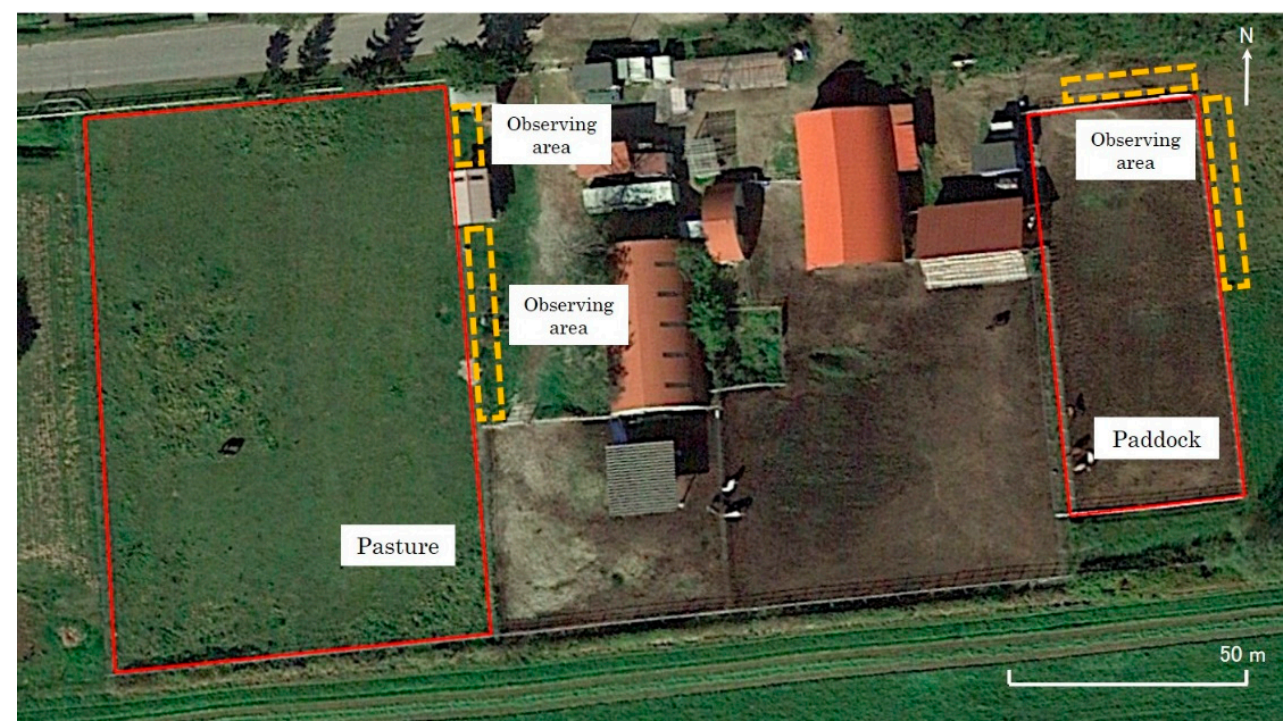

Figure 1. Experimental pasture and paddock and observing area. Observer changed observing position during observation to see target horse clearly.

\subsection{Drone Operation}

A takeoff point was selected at least $10 \mathrm{~m}$ from the horses ensuring a safe position with regards to both the horses and the pilots. The drone ascended to an altitude of $60 \mathrm{~m}$ at the takeoff point and then traveled to a position directly above the focal horse. Flight altitudes were set to four levels $(60,50,40$, and $30 \mathrm{~m})$ to investigate the horses' reactions to the drones and verify the observed behavior. These levels were chosen because an altitude over $60 \mathrm{~m}$ was deemed too high for accurate observation based on the findings of a preliminary experiment (unpublished data), while an altitude under $30 \mathrm{~m}$ is classified as restricted under Japanese law.

Video recording was initiated when the drone reached an altitude of $60 \mathrm{~m}$. After $5 \mathrm{~min}$ recorded video, the altitude of the drone was reduced to $50 \mathrm{~m}$, and another $5 \mathrm{~min}$ video was obtained. This process was repeated for $40 \mathrm{~m}$ and $30 \mathrm{~m}$ altitude observations. A single pilot operated the drone on all flights. The pilot monitored the drone controller's display during the flights and operated the drone to follow the horses with minimal movement until the focal horse moved outside the filming range. 


\subsection{Direct and Drone Video Observations}

Direct continuous observations were made by one observer familiar with the focal horses simultaneously during drone recordings. Direct continuous observations were conducted to record the time for which the target animal showed focused behaviors, including foraging, moving, standing, recumbency, and avoidance behavior; these behaviors were defined by the authors and are shown in Table 2. The observer recorded the time of each behavior from observer's area shown in Figure 1. The observer changed the position to follow the target horse inside observer's area. The distance between horses and the observer was a maximum of $50 \mathrm{~m}$. Using the drone, the pilot continuously recorded the horse's behavior for $5 \mathrm{~min}$ at each drone altitude level. Direct observation and video recording were conducted once per individual horse. Continuous observations of recorded videos were conducted using a 17-inch monitor in the laboratory. The observer was the same person who conducted the direct observation during the drone flight. The time of each behavior was noted by the observer by watching the drone recordings. Videos were observed between November and December 2017.

Table 2. Ethogram of recorded behaviors.

\begin{tabular}{|c|c|}
\hline Behavior & Observation \\
\hline Foraging & $\begin{array}{l}\text { Muzzle lowered to the ground, grasping grass or hay with lips and tongue, } \\
\text { chewing and swallowing grass. } \\
\text { Moving less than three consecutive steps in } 1 \text { min while eating was not } \\
\text { recorded as a movement. }\end{array}$ \\
\hline Moving & Walking more than one step without eating. \\
\hline Standing & Standing still without grazing, moving, or suckling. \\
\hline Recumbency & Lying down on the ground \\
\hline Avoidance & Horses seem to try to escape from the drone. \\
\hline Others & $\begin{array}{c}\text { Behaviors not described above (e.g., self/mutual grooming, defecation, } \\
\text { urination). }\end{array}$ \\
\hline
\end{tabular}

\subsection{Statistical Analysis}

The correlation coefficients (Cohen's kappa coefficient) between recorded behavioral data (duration of each behavior in seconds) from the direct and drone video observations were calculated for each altitude using a Bell Curve in Microsoft Excel 2016.

\section{Results}

\subsection{Recorded Behaviors}

None of the horses displayed avoidance behavior at any of the flight altitudes. Furthermore, the observer could quickly distinguish between any two horses from one paddock or pasture at all altitudes without difficulty. Figure 2 shows examples of the video quality for each altitude. There was an instance at $30 \mathrm{~m}$ altitude where a pair of horses could not be recorded at once because the experimental paddock was larger than the viewing angle. This pair was a dam (Horse C) and a 6-month-old foal (Horse D). The field of view of the drone was set according to the position of the dam; therefore, the foal's data were unavailable in this case. Figure 3 shows this case as "Not Recorded." Not recorded were also recorded in cases of force landing of drone and drone's SD card error. 
(a) $60 \mathrm{~m}$

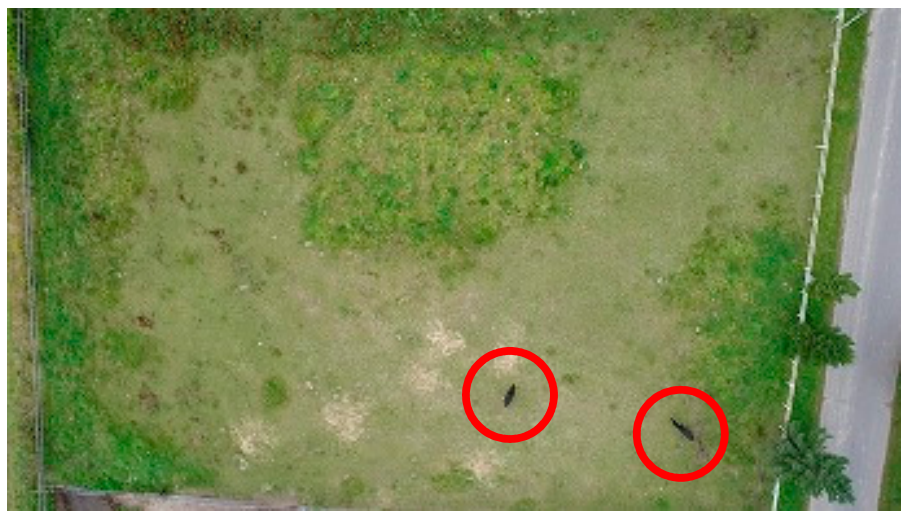

(b) $50 \mathrm{~m}$

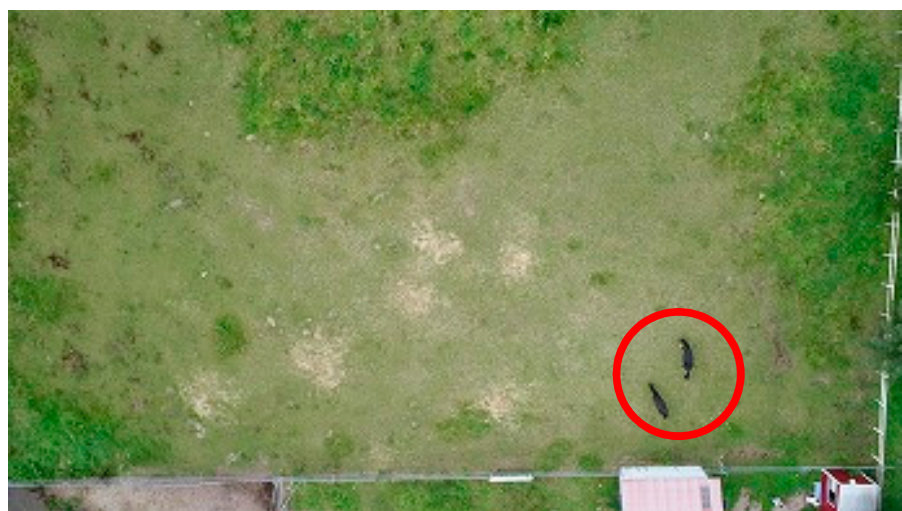

(c) $40 \mathrm{~m}$

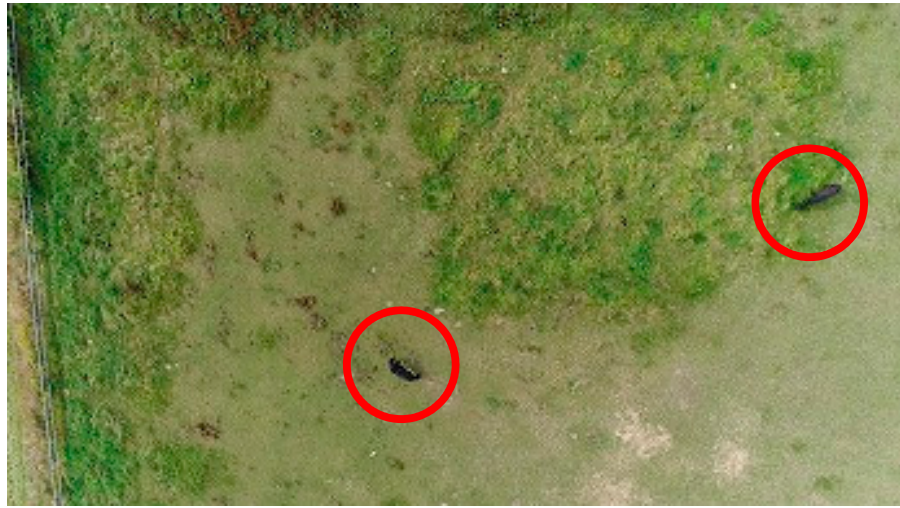

(d) $30 \mathrm{~m}$

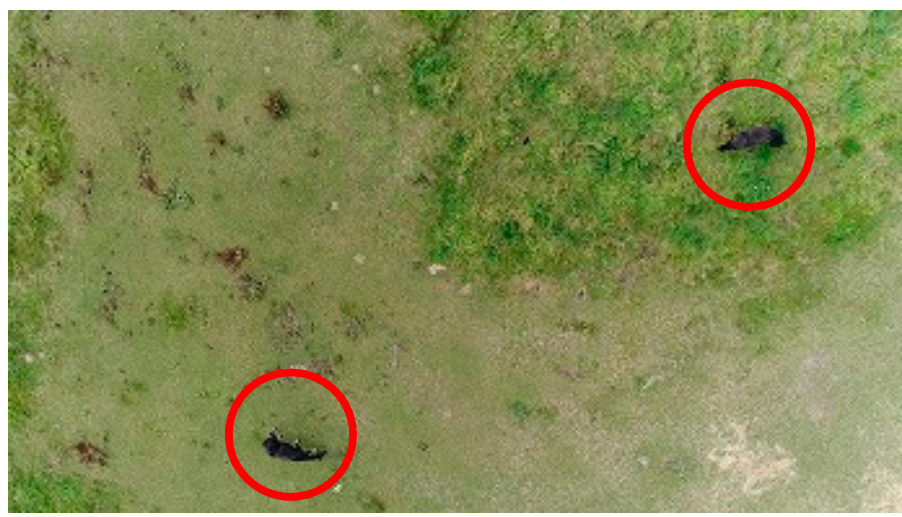

Figure 2. Sample images of a horse pair (H and I) at each flight altitude. Red circle indicates location of horses at (a) $60 \mathrm{~m}$, (b) $50 \mathrm{~m}$, (c) $40 \mathrm{~m}$, and (d) $30 \mathrm{~m}$ flight altitudes. 
(a) $60 \mathrm{~m}$

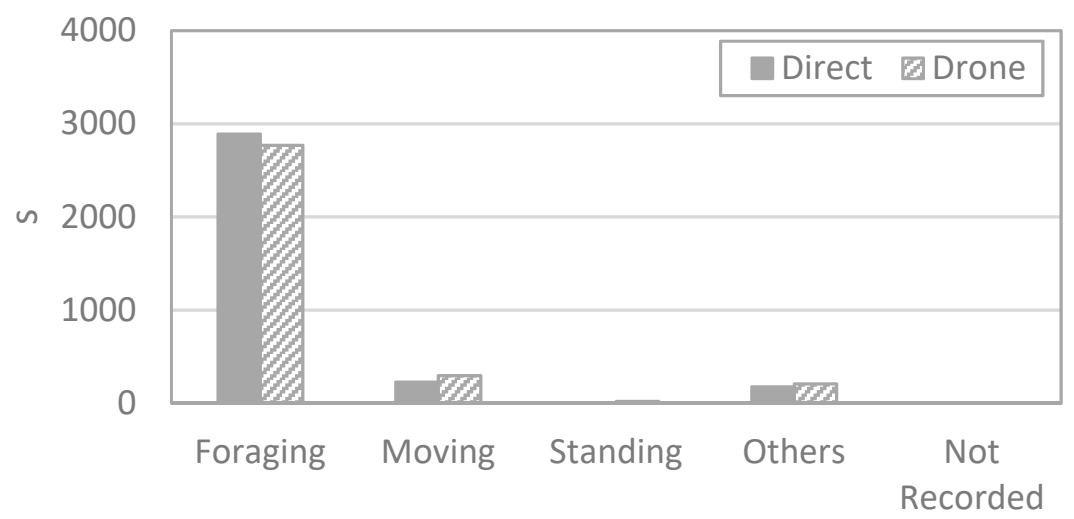

(b) $50 \mathrm{~m}$

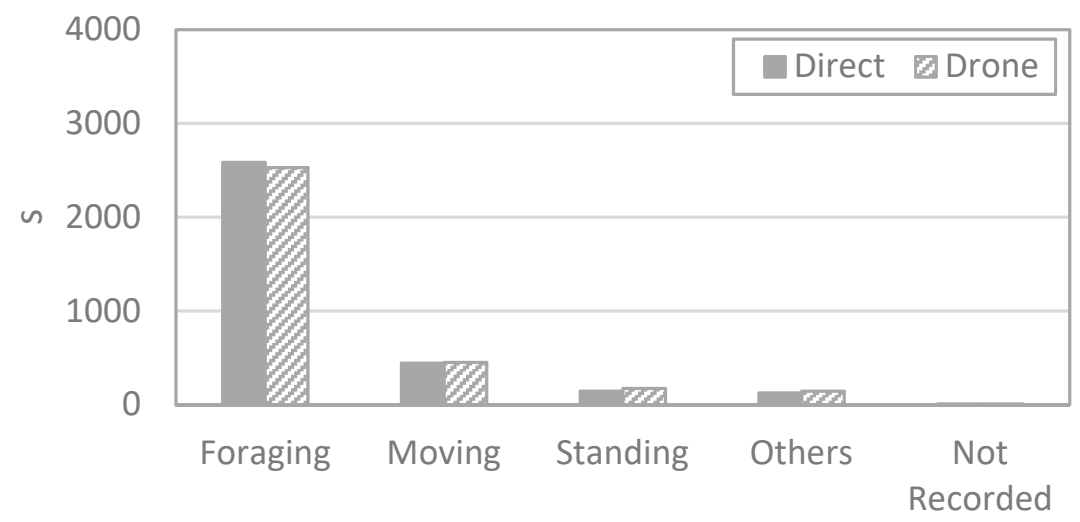

(c) $40 \mathrm{~m}$

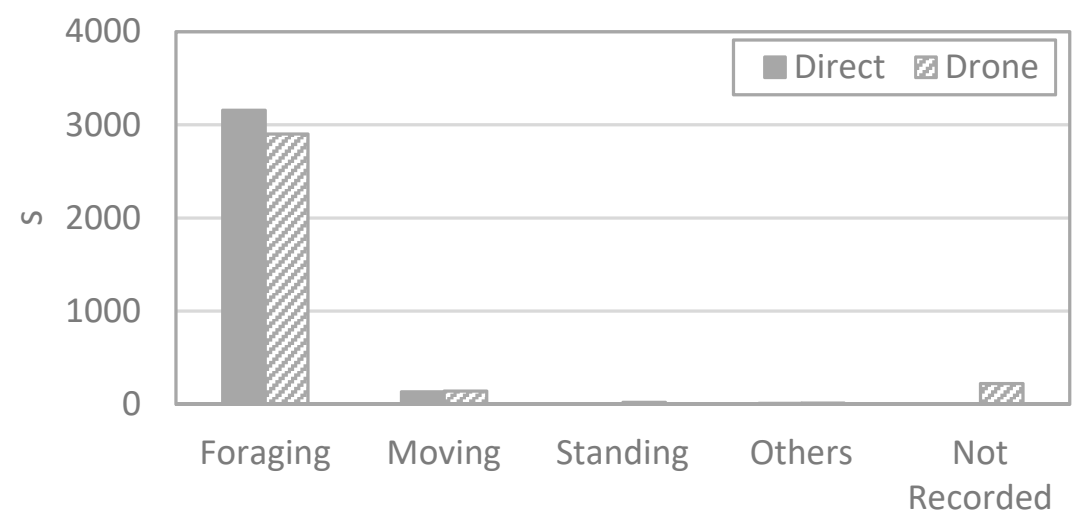

(d) $30 \mathrm{~m}$

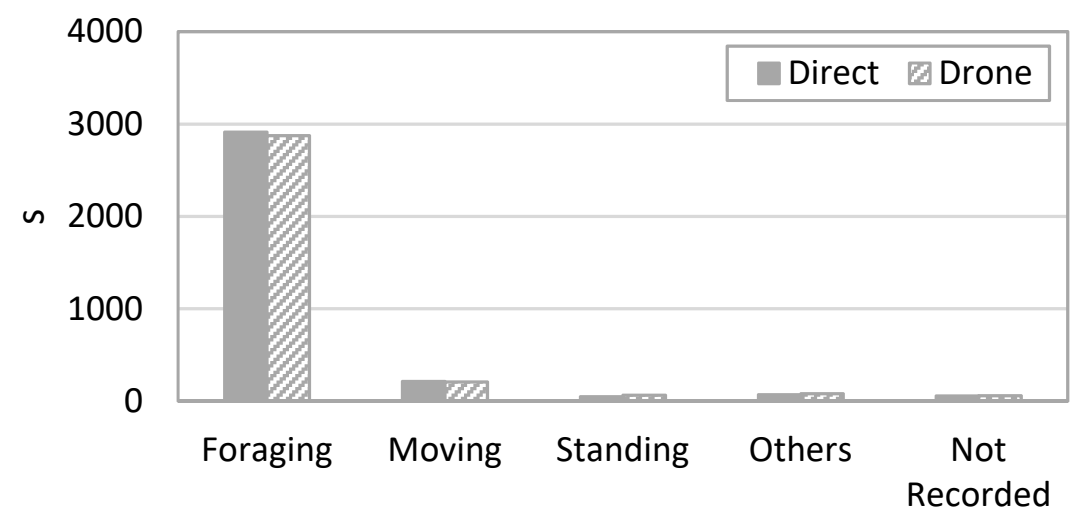

Figure 3. Recorded times of behaviors of 11 horses from direct and drone observations at each flight altitude. (a) $60 \mathrm{~m}$, (b) $50 \mathrm{~m}$, (c) $40 \mathrm{~m}$, and (d) $30 \mathrm{~m}$ flight altitudes. 


\subsection{Behavior Details}

Figure 3 shows the time spent by the 11 horses for each behavior at each altitude. Eating was the most common behavior recorded in both the direct and the drone video observations during the 5-min behavioral observations and was observed for 75-95\% of the total observation time.

The correlation coefficients (Cohen's kappa coefficient) of direct and video observations at different altitudes are shown in Table 3 . All coefficients per altitude (as illustrated in Table 3) were significant $(p<0.01)$.

Table 3. Cohen's kappa coefficient for each altitude.

\begin{tabular}{cc}
\hline Altitude & Coefficient \\
\hline $60 \mathrm{~m}$ & $0.60^{* * * *}$ \\
$50 \mathrm{~m}$ & $0.76^{* * *}$ \\
$40 \mathrm{~m}$ & $0.47^{* * *}$ \\
$30 \mathrm{~m}$ & $0.71^{* * *}$ \\
\hline
\end{tabular}

$\overline{* * *: p<0.01 .}$

\section{Discussion}

\subsection{Impact of Drone Flight}

The impact of drone flight on the behavior of horses is often discussed as an important factor when a drone is flown over them. The horses in this experiment did not show avoidance behavior during the drone flight, indicating that the drone did not affect the horses' behavior even at an altitude of $30 \mathrm{~m}$, as long as it was stationary in the air. However, the drone may not have affected the horses' behavior because they were accustomed to the existence of humans and the operation of equipment. Nonetheless, the impact of drones on free-roaming bears was quantified previously [18]; they exhibited a stress response to unmanned aerial vehicle flights, as evidenced by their elevated heart rates, but they rarely showed a behavioral response. Our experiment recorded only behavioral data; therefore, there is a possibility that there was a potential stress response that did not appear in their behavior. Furthermore, since the drone remained stationary in the air in this experiment, it will be necessary for future studies to investigate how horses react to drone flights when they follow horses in a rapid motion with accompanying motor noise. Moreover, it was reported that horses spend $14-17 \mathrm{~h}$ grazing per day (i.e., $60-70 \%$ of the day) [19]. The present study results are consistent with those of previous studies, suggesting that the horses exhibited natural behavior during the drone flight. Therefore, drones at appropriate altitudes do not affect horses' behavior.

\subsection{Drone Position}

Individual identification of each horse was possible at the highest flight altitude of $60 \mathrm{~m}$ when the observer had sufficient knowledge of the horses. There was a difference in the images of the horses acquired at each altitude. For example, at the altitudes of $60 \mathrm{~m}$ and $50 \mathrm{~m}$, the viewing range was larger than that at $40 \mathrm{~m}$ and $30 \mathrm{~m}$, and the paddock or pasture locations were maintained entirely inside the viewing range. The risk of one individual of a pair exiting the viewing range was reduced when the altitude was higher; however, the images became smaller, making detailed behavioral observations more difficult.

The dam-foal pair in one of the cases could not be viewed simultaneously at an altitude of $30 \mathrm{~m}$ because the field of view of the camera was limited. However, a previous study reported a dam-foal distance of $20 \mathrm{~m}$ for a similar case where the field of view of the camera was small [20]. Therefore, these results suggest that it is necessary to consider the expected range of activity and interindividual distances of the target horses while deciding the drone altitude and the flight schedules. In addition, the horses were observed simultaneously as pairs in a small pasture in this experiment. Thus, it would be necessary to take measures, such as painting the horses for individual identification and moving the drone to follow 
the focal horse, if the number of focal horses to be observed or the experimental pasture area increases.

\subsection{Possibility of Behavioral Observations}

The Cohen's kappa coefficients were significant $(p<0.01)$ at all altitudes. This shows that observing the video recorded by drones can be an alternative to direct observation when observing horse behaviors similar to those targeted in this study.

However, the observer was able to identify that the focal horse was foraging but could not distinguish what is foraged even at the lowest altitude of $30 \mathrm{~m}$. This was because the drone stayed directly above the focal horses; therefore, the observer could only see the position of the horse's head. The observer might be able to identify whether the horses consumed grass or hay if the drone was flown at an appropriate position and angle, which would allow the horse's mouth to be in a better observational position. This indicates the necessity to consider the recording distance, direction, and angle in advance, depending on the observed behavior.

\section{Conclusions}

In conclusion, since the Cohen's kappa coefficients were significant at all altitudes, we concluded that an observer viewing drone footages from altitudes of $30-60 \mathrm{~m}$ could identify horses' targeted behaviors this study with high accuracy compared to direct observations. However, further study is needed to clarify behaviors that are not targeted in this study, and experiments that seek a more direct way to the practical application of drones to horse management are required.

Author Contributions: Conceptualization: T.S. and M.K.; methodology: T.S. and M.K.; formal analysis: T.S. and M.K.; investigation: T.S. and M.K.; resources: T.S. and M.K.; data curation: T.S. and M.K.; writing—original draft preparation: T.S. and M.K.; writing—review and editing: T.S.; and project administration: T.S. All authors read and agreed to the published version of the manuscript.

Funding: This research received no external funding.

Data Availability Statement: Not applicable.

Acknowledgments: Appropriate and essential comments from different individuals contributed significantly to the quality of this paper.

Conflicts of Interest: The authors declare no conflict of interest.

\section{References}

1. Hodgson, A.; Kelly, N.; Peel, D. Unmanned aerial vehicles (UAVs) for surveying marine fauna: A dugong case study. PLoS ONE 2013, 8, e79556. [CrossRef] [PubMed]

2. Vermeulen, C.; Lejeune, P.; Lisein, J.; Sawadogo, P.; Bouché, P. Unmanned aerial survey of elephants. PLoS ONE 2013, 8, e54700. [CrossRef] [PubMed]

3. Uehara, H.; Hashimoto, K.; Yoshida, R.; Yoshino, T.; Matsumoto, F.; Yoshida, T. A report on Red-crowned crane monitoring by unmanned aerial vehicle at Japanese crane reserve in Kushiro City. J. Rakuno Gakuen Univ. 2016, 41, 93-96. (In Japanese)

4. Ratcliffe, N.; Guihen, D.; Robst, J.; Crofts, S.; Stanworth, A.; Enderlein, P. A protocol for the aerial survey of penguin colonies using UAVs. J. Unmanned Veh. Sys. 2015, 3, 95-101. [CrossRef]

5. Pfeifer, C.; Rümmler, M.; Mustafa, O. Assessing colonies of Antarctic shags by unmanned aerial vehicle (UAV) at South Shetland Islands, Antarctica. Antarct. Sci. 2021, 33, 133-149. [CrossRef]

6. Fudala, K.; Bialik, R.J. Breeding Colony Dynamics of Southern Elephant Seals at Patelnia Point, King George Island, Antarctica. Remote Sens. 2020, 12, 2964. [CrossRef]

7. Shingu, Y.; Kondo, S.; Hata, H. Differences in grazing behavior of horses and cattle at the feeding station scale on woodland pasture. Anim. Sci. J. 2010, 81, 384-392. [CrossRef] [PubMed]

8. Souris, A.; Kaczensky, P.; Julliard, R.; Walzer, C. Time budget-, behavioral synchrony- and body score development of a newly released Przewalski's horse group Equus ferus przewalskii, in the Great Gobi B strictly protected area in SW Mongolia. Appl. Anim. Behav. Sci. 2007, 107, 307-321. [CrossRef] [PubMed]

9. Rivera, E.; Benjamin, S.; Nielsen, B.; Shelle, J.; Zanella, A.J. Behavioral and physiological responses of horses to initial training: The comparison between pastured versus stalled horses. Appl. Anim. Behav. Sci. 2002, 78, 235-252. [CrossRef] 
10. Merkies, K.; Franzin, O. Enhanced Understanding of Horse-Human Interactions to Optimize Welfare. Animals 2021, 11, 1347. [CrossRef] [PubMed]

11. Inoue, S.; Yamamoto, S.; Ringhofer, M.; Mendonça, R.S.; Pereira, C.; Hirata, S. Spatial positioning of individuals in a group of feral horses: A case study using drone technology. Mamm. Res. 2019, 64, 249-259. [CrossRef]

12. Inoue, S.; Yamamoto, S.; Ringhofer, M.; Mendonça, R.S.; Hirata, S. Lateral position preference in grazing feral horses. Ethology 2020, 126, 111-119. [CrossRef]

13. Ringhofer, M.; Go, C.K.; Inoue, S.; Mendonça, R.S.; Hirata, S.; Kubo, T.; Ikeda, K.; Yamamoto, S. Herding mechanisms to maintain the cohesion of a harem group: Two interaction phases during herding. J. Ethol. 2020, 38, 71-77. [CrossRef]

14. McDonnell, S.; Torcivia, C. Preliminary Proof of the Concept of Wild (Feral) Horses Following Light Aircraft into a Trap. Animals 2020, 10, 80. [CrossRef] [PubMed]

15. Rivas, A.; Chamoso, P.; González-Briones, A.; Corchado, J.M. Detection of cattle using drones and convolutional neural networks. Sensors 2018, 18, 2048. [CrossRef] [PubMed]

16. Vayssade, J.A.; Arquet, R.; Bonneau, M. Automatic activity tracking of goats using drone camera. Comput. Electron. Agric. 2019, 162, 767-772. [CrossRef]

17. Ministry of Land, Infrastructure, Transport and Tourism. Civil Aeronaut. Act. 2006.

18. Ditmer, M.A.; Vincent, J.B.; Werden, L.K.; Tanner, J.C.; Laske, T.G.; Iaizzo, P.A.; Garshelis, D.L.; Fieberg, J.R. Bears show a physiological but limited behavioral response to unmanned aerial vehicles. Curr. Biol. 2015, 25, 2278-2283. [CrossRef] [PubMed]

19. Martinson, K.L.; Siciliano, P.D.; Sheaffer, C.C.; McIntosh, B.J.; Swinker, A.M.; Williams, C.A. A review of equine grazing research methodologies. J. Equine Vet. Sci. 2017, 51, 92-104. [CrossRef]

20. Sato, F.; Tanabe, T.; Murase, H.; Tominari, M.; Kawai, M. Application of a wearable GPS unit for examining interindividual distances in a herd of thoroughbred dams and their foals. J. Equine Sci. 2017, 28, 13-17. [CrossRef] [PubMed] 